Article

\title{
Graphene/Epoxy Coating as Multifunctional Material for Aircraft Structures
}

\author{
Tullio Monetta, Annalisa Acquesta * and Francesco Bellucci \\ Department of Chemical, Materials and Production Engineering, University of Naples Federico II, \\ Piazzale Tecchio 80, 80125 Naples, Italy; E-Mails: monetta@unina.it (T.M.); bellucci@unina.it (F.B.) \\ * Author to whom correspondence should be addressed; E-Mail: annalisa.acquesta@unina.it; \\ Tel.: +39-081-768-2152.
}

Academic Editor: Rafic Ajaj

Received: 12 June 2015 / Accepted: 24 June 2015 / Published: 30 June 2015

\begin{abstract}
Recently, the use of graphene as a conductive nanofiller in the preparation of inorganic/polymer nanocomposites has attracted increasing interest in the aerospace field. The reason for this is the possibility of overcoming problems strictly connected to the aircraft structures, such as electrical conductivity and thus lightning strike protection. In addition, graphene is an ideal candidate to enhance the anti-corrosion properties of the resin, since it absorbs most of the light and provides hydrophobicity for repelling water. An important aspect of these multifunctional materials is that all these improvements can be realized even at very low filler loadings in the polymer matrix. In this work, graphene nanoflakes were incorporated into a water-based epoxy resin, and then the hybrid coating was applied to Al 2024-T3 samples. The addition of graphene considerably improved some physical properties of the hybrid coating as demonstrated by Electrochemical Impedance Spectroscopy (EIS) analysis, ameliorating anti-corrosion performances of raw material. DSC measurements and Cross-cut Test showed that graphene did not affect the curing process or the adhesion properties. Moreover, an increment of water contact angle was displayed.
\end{abstract}

Keywords: multifunctional material; graphene/epoxy coatings; corrosion resistance 


\section{Introduction}

Use of graphene as nanofiller in polymer matrices to form advanced multifunctional materials is one of the most promising routes in aerospace, automobile and defence industries [1,2]. The construction of a 3D compactly interconnected graphene network can offer a significant increase in electrical and thermal conductivity of polymer composites. Since a growing and inevitable issue for aircraft structures is corrosion protection, graphene, owing to its barrier properties, could be used to enhance corrosion resistance. The surprising finding is that a very small amount of graphene can significantly improve the physical properties of neat polymers. These outstanding properties of the graphene can be combined with polymer matrix properties to develop multifunctional coatings. In recent years, the number of publications about graphene-based multifunctional materials has increased dramatically [3-12], but in literature very few papers use these nanocomposites as coatings. In particular, research about improvement of corrosion resistance applying graphene/epoxy coatings are even less common [13-16]. No paper addresses the possibility of using a water-based epoxy resin, considering the new regulations about the emission of volatile organic compounds [17], and no paper applies the graphene-based coating to the most common of aircraft alloys, that is, Al 2024-T3. Due to the possible multifunctional properties of the graphene/epoxy coating, this study, starting from the evaluation of the barrier properties and adhesion, continues on to an analysis of the electrical conductivity, the UV resistance and the galvanic coupling between aluminium substrate and graphene nanoflakes. The motivation is to examine if the addition of graphene can improve the above physical characteristics of neat polymer. In present paper, results obtained by studies on barrier and adhesion properties are showed.

The graphene/epoxy coating was prepared by incorporating a very small amount of graphene nanoflakes into a water-based epoxy resin, mixing in an ultrasonic bath and applying the hybrid coating to 2024-T3 aluminium alloy panels. The analysis of impedance and the capacitance of graphene/epoxy coated aluminium alloys were studied using electrochemical impedance spectroscopy (EIS). DSC measurements were performed to evaluate the possible influence of graphene on the curing process of the coating. The resistance of the coating to separation from aluminium alloy substrate was tested by means of a cross-cut test. The hydrophobic characteristics offered by graphene were investigated using contact angle measurements with water sessile drops. The results of the analysis were compared with a coating made of epoxy resin without filler content.

\section{Experimental Section}

\subsection{Materials}

The graphene nanoflakes were supplied by Cometox (Milano, Italy), with the commercial name of C500. Raman (Bruker, Ettlingen, Germany), X-ray diffraction (XRD; PANalytical, Cambridge, UK) and X-ray photoelectron spectrometer (XPS; Kratos Co., Manchester, UK) analysis of the as-received graphene, shown on the supplier's website, are shown in Figure 1. 
XRD Patterns of C - Grades

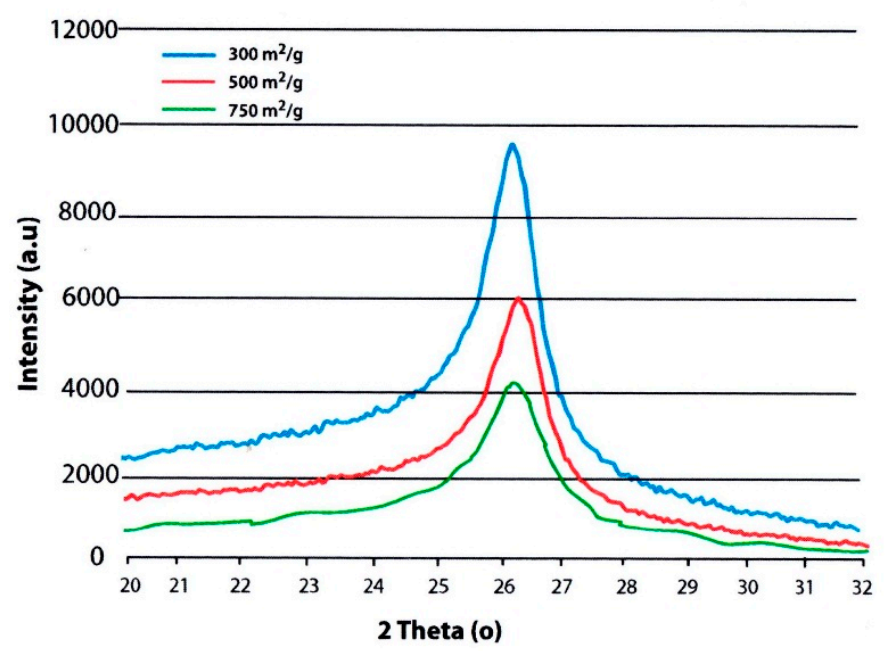

(a)

Raman Spectroscopy of C Grades

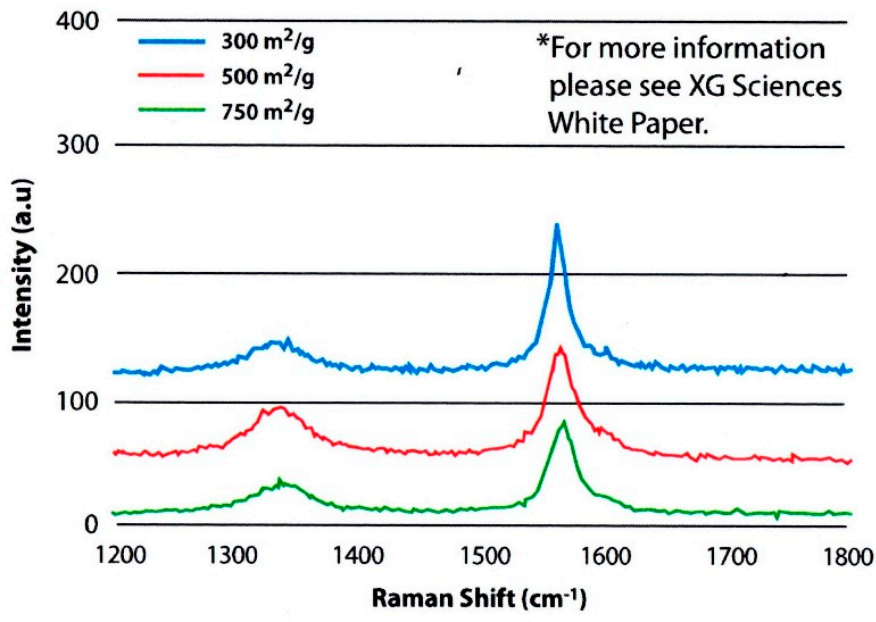

(b)

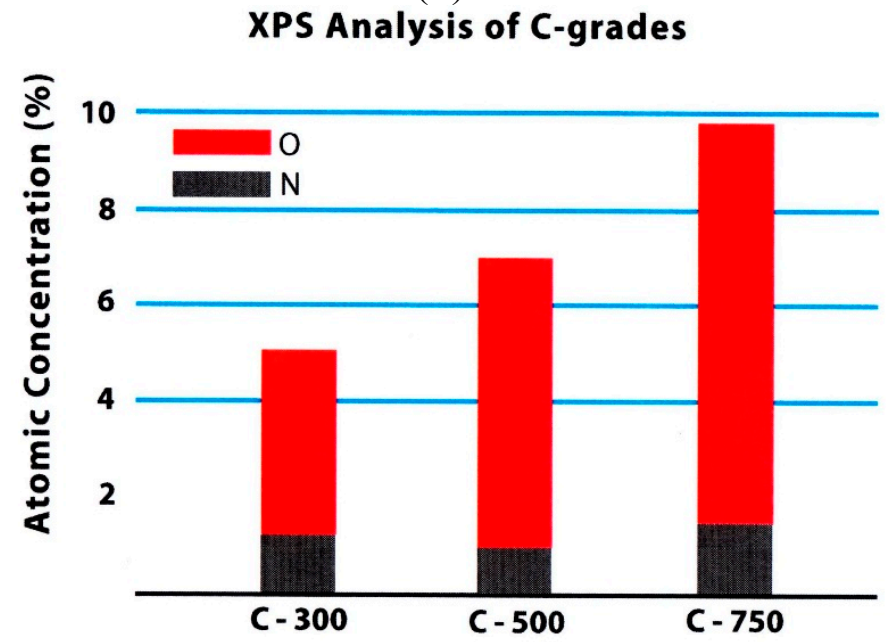

(c)

Figure 1. XRD (a), Raman (b) and XPS (c) of the as-received graphene nanoflakes. 
In particular, the graphene nanoflakes were $2 \mu \mathrm{m}$ in diameter, few nanometer in thickness and with an average surface area of $500 \mathrm{~m}^{2} / \mathrm{g}$. One component epoxy system without corrosion inhibitors and a curing agent provided by Sikkens were used as polymer matrix. The mass ratio between the resin and curing agent was 4:1. The metals used were AA 2024-T3 aluminium alloy panels. Before coating the samples, the surfaces are cleaned with ethanol and acetone.

\subsection{Graphene/Epoxy Coating Preparation}

The epoxy resin and $1 \mathrm{wt} \%$ of graphene nanoflakes were mixed. In order to disperse graphene a sonication bath was carried out for 20 min with a frequency of $50 \mathrm{~Hz}$. Next, curing agent was added and mixed using a magnetic stirrer for other $20 \mathrm{~min}$. The hybrid coating was, finally, spread on AA2024 aluminium alloy panel by means of spiral bar applicator and cured at room temperature for $24 \mathrm{~h}$ (Figure 2). The thickness of coatings, with or without graphene nanoflakes, measured using an Elcometer thickness instrument (IMCD Italia S.p.A, Milano, Italy), was about $28 \pm 1.2 \mu \mathrm{m}$.

It can be seen that graphene gives a gray colour to the paint. Certainly this effect can be relevant if the colour of paint becomes an important characteristic.

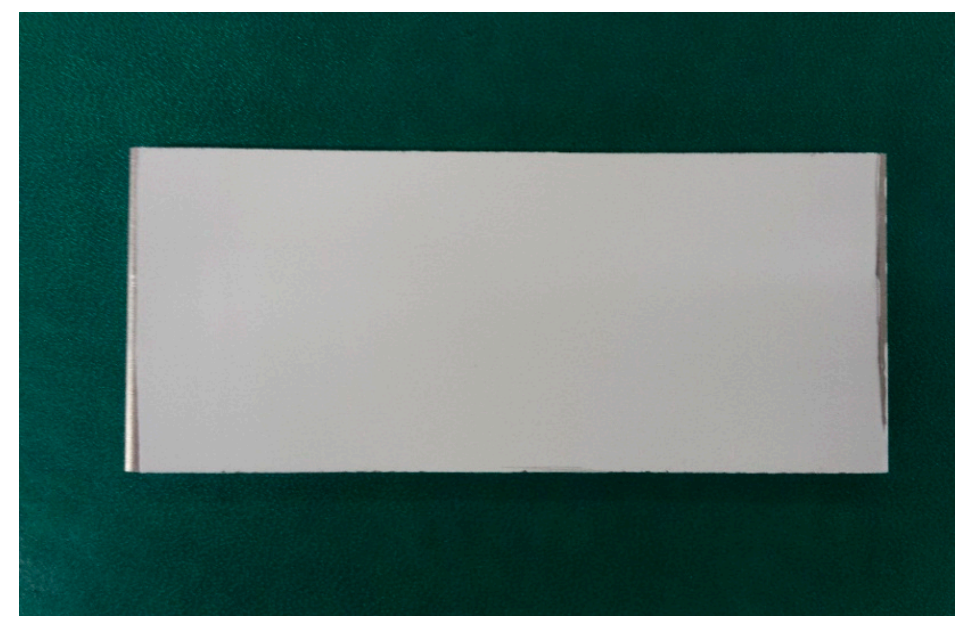

(a)

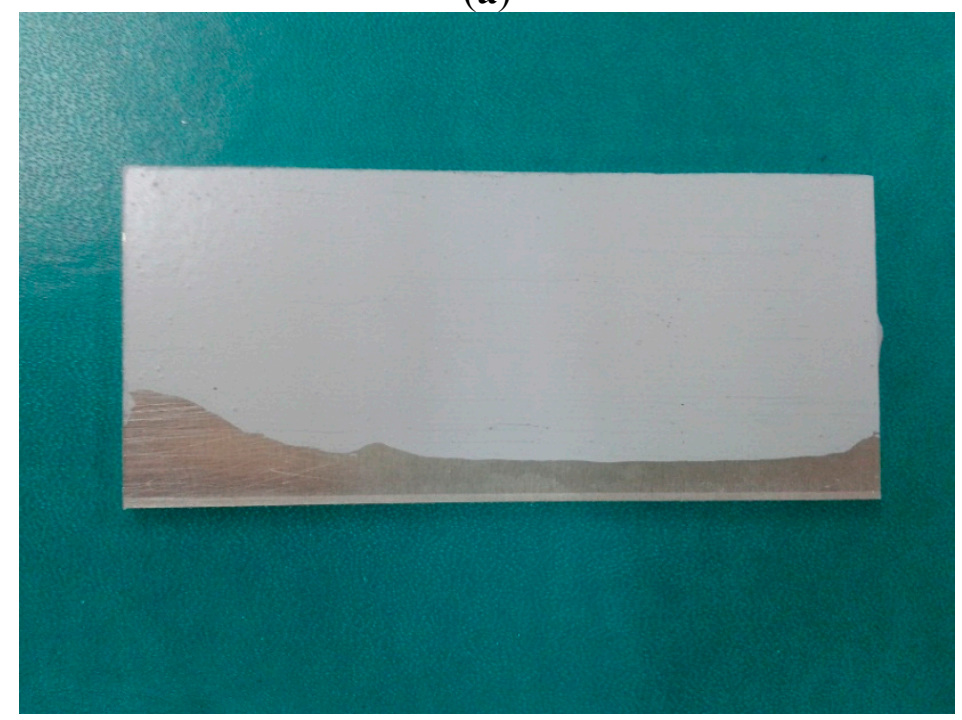

(b)

Figure 2. AA 2024-T3 aluminium alloy coated with epoxy resin (a) and graphene/epoxy resin (b). 


\subsection{Characterizations}

\subsubsection{Electrochemical Tests}

Electrochemical tests were performed in an $3.5 \mathrm{wt} \%$ aerated aqueous solution of $\mathrm{NaCl}$, using a conventional 3-electrode system with the graphene-filled coating as the working electrode, a platinum as the counter electrode and a saturated calomel electrode (SCE) as reference electrode. A Solartron 1255 Frequency Response Analyzer (Photoanalytical, Milano, Italy) connected to a Solartron 1286 potentiostat/galvanostat (Photoanalytical, Milano, Italy) was employed. In particular, electrochemical impedance spectroscopy (EIS) analysis (Photoanalytical, Milano, Italy) and capacitance tests were performed. The former is a powerful analysis technique to study the corrosion protective properties of coatings over metals. It has been used to characterize the corrosion behaviour of coated aluminium alloys immersed in aggressive solutions [18-20].

For EIS measurements, the amplitude of the sinusoidal signal was $10 \mathrm{mV}$, the frequency ranging from $10^{-2}$ to $10^{5} \mathrm{~Hz}$. The exposed area was $1 \mathrm{~cm}^{2}$. Tests were carried out for up to 10 days of immersion. Results were taken by analyzing the Bode plots.

Capacitance tests were performed at open potential circuit (OCP) with an AC amplitude of $40 \mathrm{mV}$. The excitation frequency was $6.5 \mathrm{kHz}$. An immersion time of $20 \mathrm{~h}$ was chosen.

All the measurements were conducted at room temperature $\left(25^{\circ} \mathrm{C}\right)$. All trials were repeated at least three times to ensure reproducibility and accuracy of the measurements.

\subsubsection{Thermal Analysis}

The curing process of both the graphene-filled and unfilled resin was observed by taking $10 \mathrm{mg}$ of sample into aluminum pan. This was placed in sample cell of the instrument, a Mettler Toledo DSC12E (Mettler-Toledo S.p.A., Milano, Italy; in a dry nitrogen atmosphere and calibrated with an Indium standard). Three scans (heating, cooling and heating again) were conducted from 30 to $250{ }^{\circ} \mathrm{C}$ with a heating rate of $10^{\circ} \mathrm{C} / \mathrm{min}$.

\subsubsection{Adhesion Test}

The influence of graphene on the adhesion of hybrid coating was examined by cross-cut test, using a cross hatch cutter (Sheen Instruments; Milano, Italy) and following ISO 2409 standard.

\subsubsection{Contact Angle Test}

Finally, the hydrophobicity of graphene/epoxy coating was determined by analysis of the water contact angle, according to ASTM D7490 and using a contact angle goniometer (Data Physics Ltd., Hailsham, UK). Water drops of $0.2 \mathrm{~mL}$ were carefully placed on the substrate with a microlitre syringe. The obtained water contact angle was the average value of ten measurements. 


\section{Results and Discussion}

\subsection{Electrochemical Test}

For a perfect insulator (i.e., an intact dry coating without defects), the phase angle should be $90^{\circ}$ due to its pure capacitive characteristics. When the electrolytic solution gradually permeates into the material, its phase angle at a given frequency decreases, due to the resistive behaviour assumed by the material and caused by entry of electrolyte. The variation of phase angles may reflect the performance of coatings [21]. In the Bode plot the peaks at different frequency range represent different time constants. The time constant appearing at high frequency range can be attributed to the coating/solution interface, while that at low frequency correspond to a corrosion process taking place at the metal/coating interface [18]. A minimum in the phase angle corresponds to a plateau in the impedance modulus [21], which represents the ability of the coating to impede the flow of current between anodic and cathodic areas.

Figure 3a,b shows the impedance modulus and phase angle of samples coated using unfilled water-based epoxy resin. The former in the medium frequency range exhibited a relevant decrease of about two orders of magnitude after one day. Although it seemed to improve up to 5 days, it decreased again after only 7 days and first blisters appeared on the surface, as shown in Figure 4 . When the solution permeates into the epoxy resin, corrosion products are formed, so the impedance decreases (curve 1d). Corrosion products seal the pores of the coating and the impedance restarts to increase (curve $2 \mathrm{~d}$ ). After 5 days the corrosion phenomenon cannot stopped, as confirmed by the trend of impedance modulus.

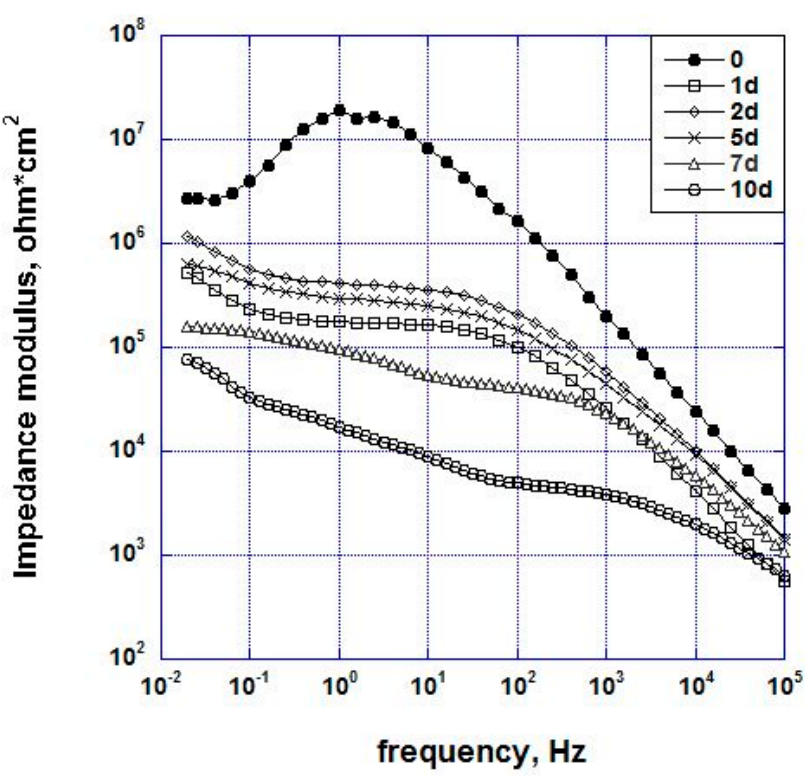

(a)

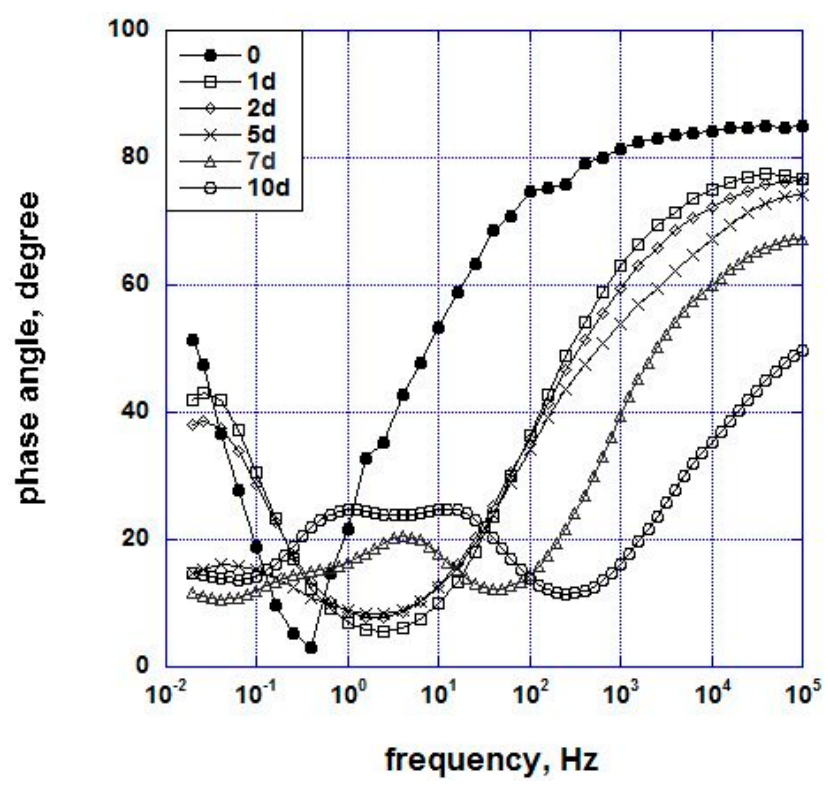

(b)

Figure 3. Bode plots for impedance modulus (a) and phase angle of sample coated with unfilled water-based epoxy resin (b). 


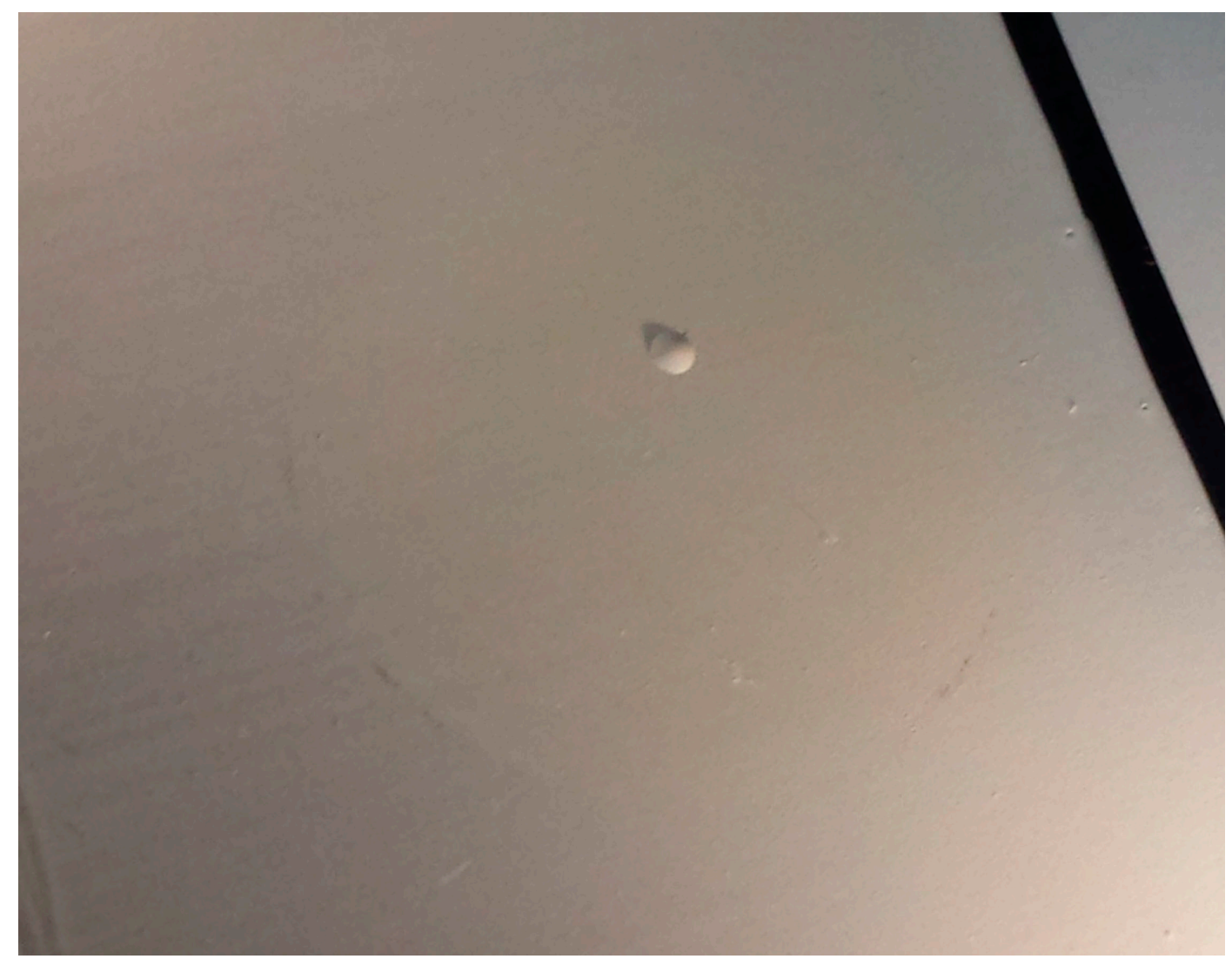

Figure 4. Blisters on sample coated with unfilled water-based epoxy resin after 7 days of immersion in aqueous $\mathrm{NaCl}$ solution.

The damage to the coating was confirmed via the phase angle plot. At beginning of the immersion, the diagram showed two time constants observable as two peaks.

The one appearing at high frequency represented the solution/coating interface, while the one at low frequency corresponded to the coating/metal interface, suggesting the presence of pores. In addition, the decrease of peaks height with exposure time indicated that the response became less capacitive; indeed, as immersion time increases, the pores permitted the solution to penetrate into the aluminium substrate, causing localised corrosion. Thus, current flowed through the defects (i.e., localised corrosion) became significant. As immersion time increased, the minimum shifted toward high frequency, suggesting that the property of coating may be affected due to the exposure.

On the other hand, the graphene/epoxy resin no relevant changes were shown throughout 10 days of exposure, as confirmed in Figure 5.

The impedance modulus showed a gradual increase. The angle phase showed one time constant. The height of peak remained unchanging with the immersion time, indicating a stable property of the coating. The impedance spectrum of sample loaded with a small amount of graphene showed an improvement of barrier properties of neat epoxy resin. 


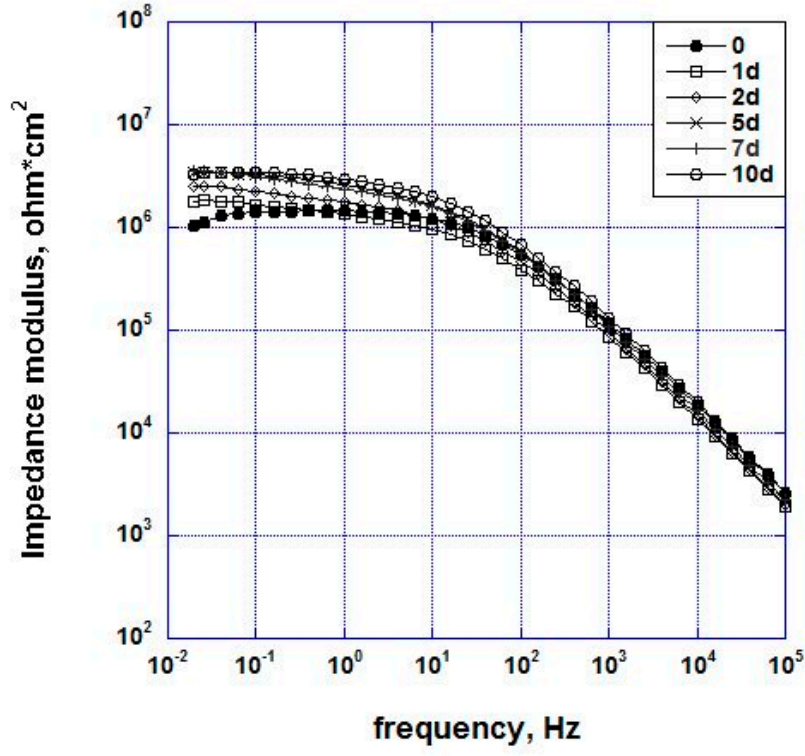

(a)

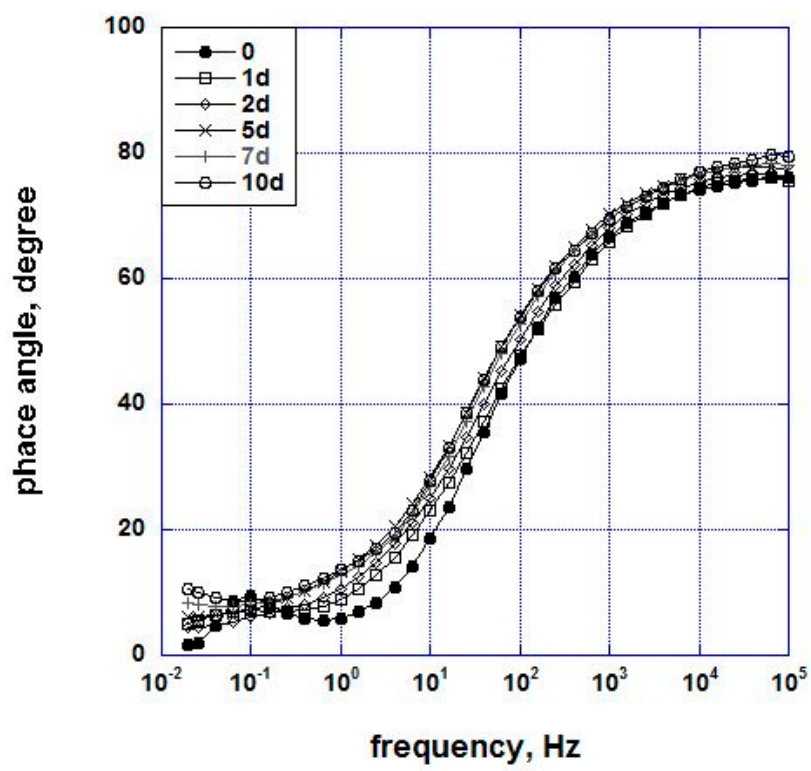

(b)

Figure 5. Bode plots for impedance modulus (a) and phase angle for sample coated with graphene/epoxy resin (b).

The electrochemical characterization also regarded the capacitance test. The results of this analysis were reported in the following figures.

The sample coated with unfilled water-based epoxy resin (Figure 6a), due to very quick water absorption, showed the capacitance response of aluminium substrate. Conversely, the capacitance curve of sample coated with graphene/epoxy resin (Figure 6b) showed a very slow process of water uptake, indicating that there was an improvement of the barrier effect offered by this kind of coating. In fact, no loss of adhesion and no blistering on the aluminium surface were found.

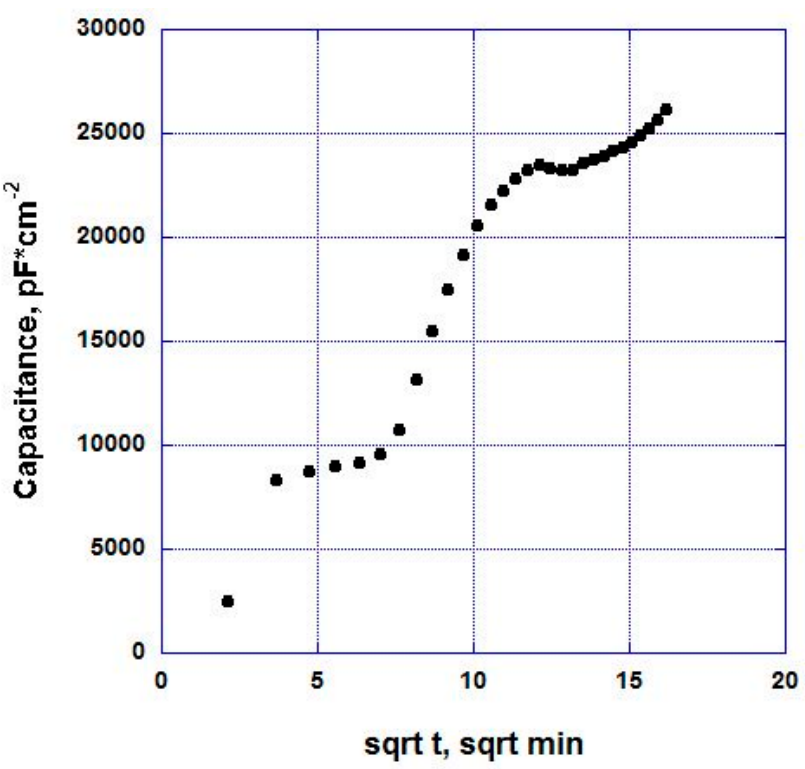

(a)

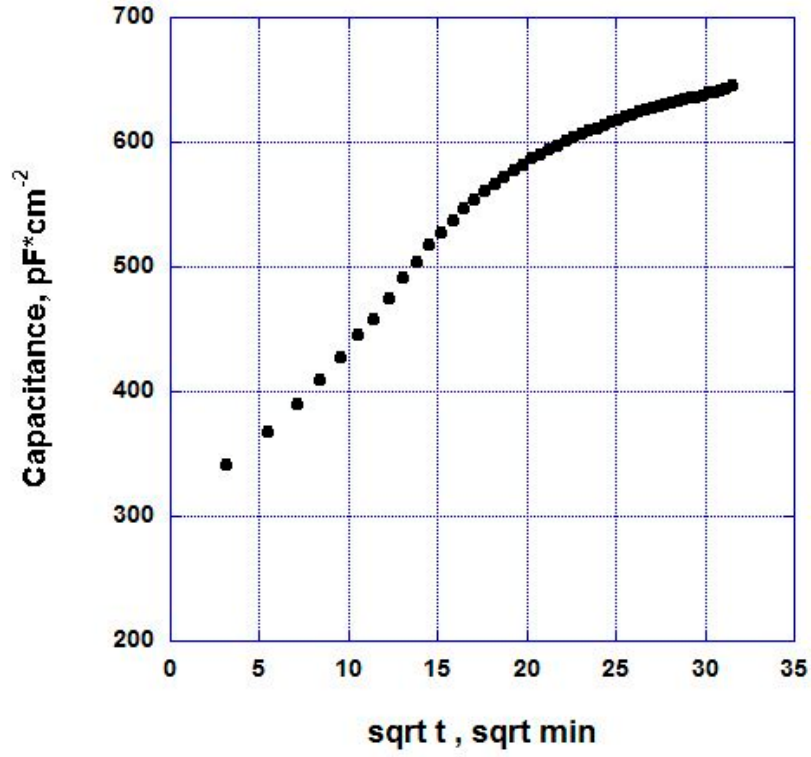

(b)

Figure 6. Capacitance curve for sample coated with unfilled water-based epoxy resin (a) and graphene/epoxy resin (b). 


\subsection{Thermal Analysis}

In order to evaluate the effect of graphene on the curing process of the coating, DSC measurements were carried out (Figure 7).

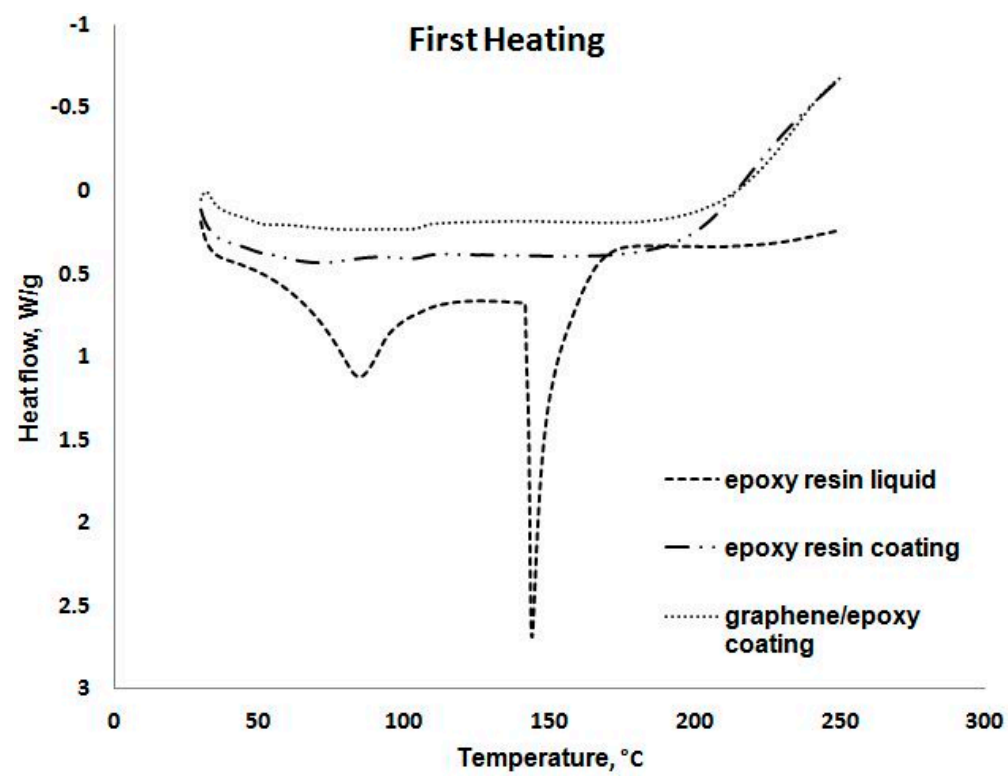

(a)

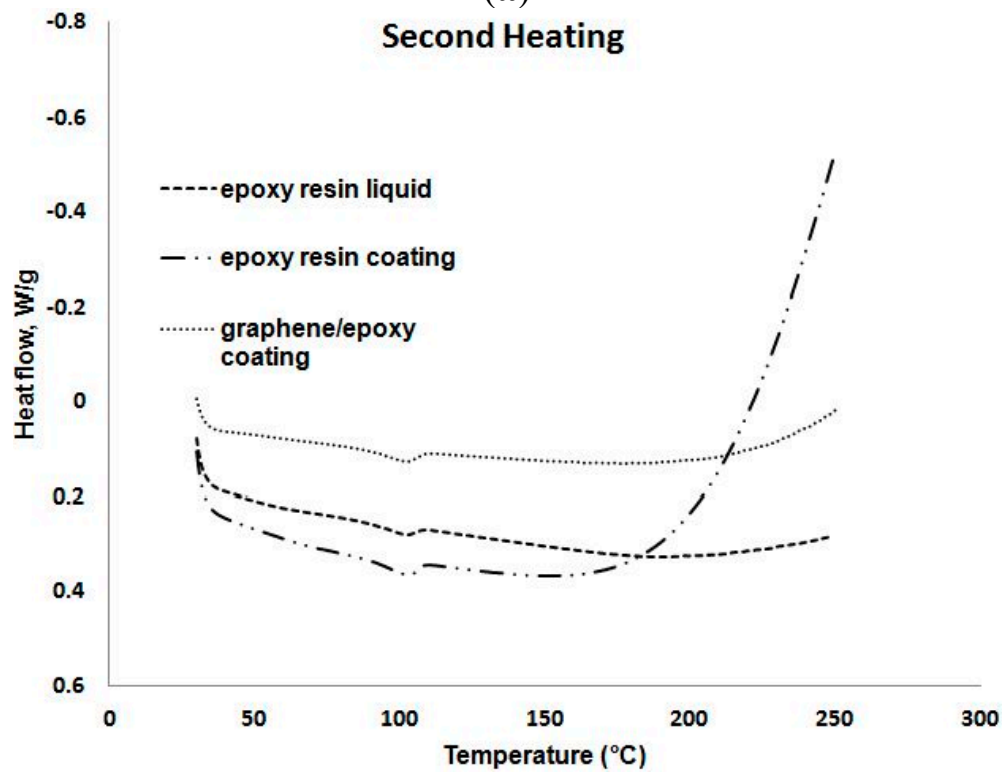

(b)

Figure 7. DSC measurements: first heating (a) and second heating (b).

As can be seen, the water-based epoxy resin not cured (called "epoxy resin liquid") presented a curing peak at approximately $150{ }^{\circ} \mathrm{C}$ and another one at about $90{ }^{\circ} \mathrm{C}$, whose nature was not identified. The latter was probably due to some constituents present in the resin.

The water-based epoxy resin that cured (called "epoxy resin coating") was not shown the curing peak, suggesting that cross-linking reactions were completed during the cure. The same curing profile was displayed by graphene/epoxy coating. This indicated that the presence of graphene did not affect the curing process. Only a small translation was shown due to the different kinds of samples. 


\subsection{Adhesion Test}

The corrosion protection properties of an organic coating most often end up linked to the barrier properties, or to the maintenance of adhesion to the substrate under chemical and electrochemical conditions imposed by the environment. Therefore, in order to investigate the influence of graphene on adhesion of the coating, a cross-cut test was performed, following the ISO 2409 standard.

According to the classification defined in ISO 2409 and ASTM D3002 and D3359, the adhesion of each coating, graphene-filled and unfilled resin (whose pictures were not reported), can be considered sufficient. Thus, the loading of graphene nanoflakes into epoxy resin did not affect the adhesion of hybrid coating.

\subsection{Contact Angle Test}

In order to analyze the improvement of hydrophobicity of coating, the water contact angle was measured over the surface of graphene-filled and unfilled resin. The obtained values were collected in Table 1.

Table 1. Water contact angle values over graphene-filled and unfilled resin.

\begin{tabular}{ll}
\hline Sample & Contact Angle (degree) \\
\hline Unfilled water epoxy resin & $60.4 \pm 1$ \\
Graphene/epoxy resin & $75.3 \pm 1$ \\
\hline
\end{tabular}

As can be seen in Figure 8, the graphene/epoxy coating showed a higher contact angle, suggesting a minor improvement of barrier properties, as confirmed by capacitance test.

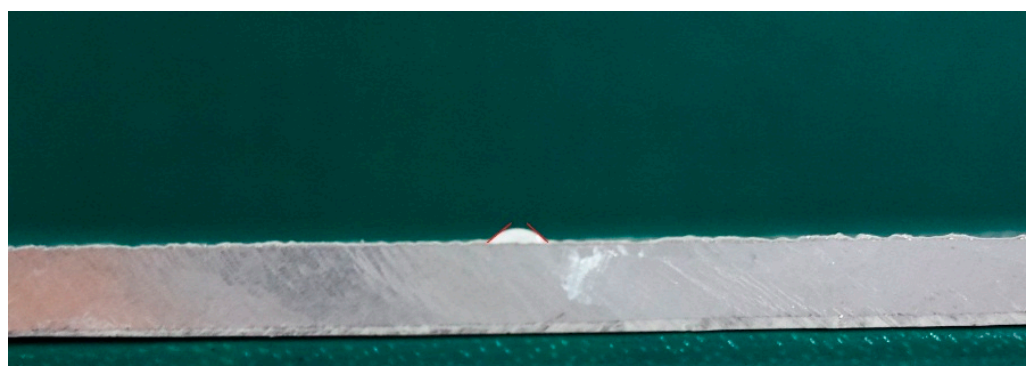

(a)

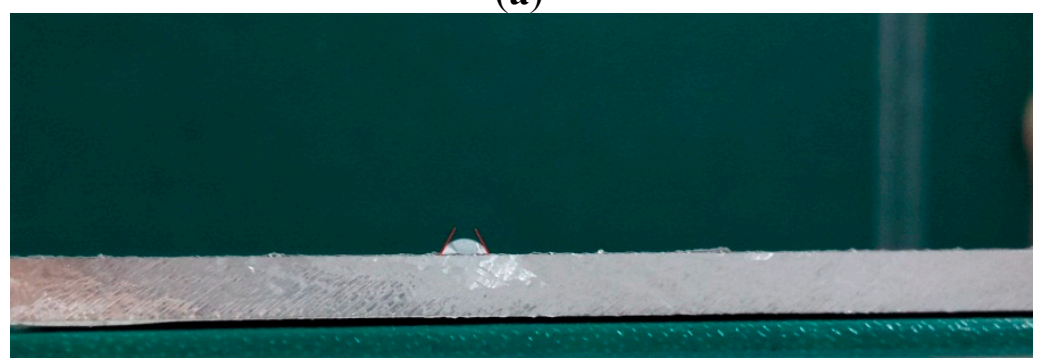

(b)

Figure 8. Contact angle of water drops over unfilled water epoxy resin (a) and graphene/epoxy resin (b). 


\section{Conclusions}

In this study, graphene/epoxy coating system are prepared by adding a very small amount of graphene nanoflakes to epoxy resin.

- The EIS test demonstrate that the addition of graphene nanoflakes significantly changes the barrier properties of epoxy resin.

- The results of capacitance analysis and water contact angle measurements show that graphene improves the barrier properties of neat epoxy resin.

- The DSC and adhesion tests demonstrate no negligible influence of graphene on the resin curing process or on adhesion properties of the coating, respectively.

- Graphene, added to a non-anticorrosive coating system, has an impressive effect on the corrosion performance of material.

\section{Author Contributions}

Annalisa Acquesta made all analysis; Tullio Monetta analyzed thermal, adhesion and contact angle tests and Francesco Bellucci analyzed Electrochemical results.

\section{Conflicts of Interest}

The authors declare no conflict of interest.

\section{References}

1. Du, J.; Cheng, H.M. The fabrication, properties, and uses of graphene/polymer composites. Macromol. Chem. Phys. 2012, 213, 1060-1077.

2. Kim, H.; Abdala, A.A.; Macosko, C.W. Graphene/polymer nanocomposite. Macromolecules 2010, 43, 6515-6530.

3. Kuilla, T.; Bhadra, S.; Yao, D.; Kim, N.H.; Bose, S.; Lee, J.H. Recent advances in graphene based polymer composites. Prog. Polym. Sci. 2010, 35, 1350-1375.

4. Potts, J.R.; Dreyer, D.R.; Bielawski, C.W.; Ruoff, R.S. Graphene-based polymer nanocomposites. Polymer 2011, 52, 5-25.

5. Jang, B.Z.; Zhamu, A. Processing of nanographene platelets (NGPs) and NGP nanocomposites: A review. J. Mater. Sci. 2008, 43, 5092-5101.

6. Yasmin, A.; Luo, J.J.; Daniel, I.M. Processing of expanded graphite reinforced polymer nanocomposites. Comp. Sci. Technol. 2006, 66, 1182-1189.

7. Zhang, W.; Yi, M.; Shen, Z.; Zhao, X.; Zhang, X.; Ma, S. Graphene-reinforced epoxy resin with enhanced atomic oxygen erosion resistance. J. Mater. Sci. 2013, 48, 2416-2423.

8. Naebe, M.; Wang, J.; Amini, A.; Khayyam, H.; Hameed, N.; Li, L.H.; Chen, Y.; Fox, B. Mechanical property and structure of covalent functionalised graphene/epoxy nanocomposites. Sci. Rep. 2014, 4, 4375.

9. Carotenuto, G.; Romeo, V.; Cannavaro, I.; Roncato, D.; Martoraa, B.; Gosso, M. Graphene-polymer composites. Mater. Sci. Eng. 2012, 40, 012018. 
10. Chieng, B.W.; Ibrahim, N.A.; Yunus, W.M.Z.W.; Hussein, M.Z.; Silveraiah, V.S.G. Graphene nanoplatelets as novel reinforcement filler in poly(lactid acid)/epoxidized palm oil green nanocomposites: Mechanical properties. Int. J. Mol. Sci. 2012, 13, 10920-10934.

11. Mukhopadhyay, P.; Gupta, R.K. Trends and frontiers in graphene-based polymer nanocomposites. Plast. Eng. 2011, 67, 32-42.

12. Kim, J.Y.; Kim, T.Y.; Suk, J.W.; Chou, H.; Jang, J.H.; Lee, J.H.; Kholmanov, I.N.; Akinwande, D.; Ruoff, R.S. Enhanced dielectric performance in polymer composite films with carbon nanotube-reduced graphene oxide hybrid filler. Small 2014, 10, 3405-3411.

13. Li, Y.; Yang, Z.; Qiu, H.; Dai, Y.; Zheng, Q.; Li, J.; Yang, J. Self-aligned graphene as anticorrosive barrier in waterborne polyurethane composite coatings. J. Mater. Chem. A 2014, 2, 14139-14145.

14. Chang, K.C.; Hsu, M.H.; Lu, H.I.; Lai, M.C.; Liu, P.J.; Hsu, C.H.; Ji, W.F.; Chuang, T.L.; Wei, Y.; Yeh, J.M.; et al. Room-temperature cured hydrophobic epoxy/graphene composites as corrosion inhibitor for cold-rolled steel. Carbon 2014, 66, 144-153.

15. Chang, K.C.; Hsu, C.H.; Lu, H.I.; Ji, W.F.; Chang, C.H.; Li, W.Y.; Chuang, T.L.; Yeh, J.M.; Liu, W.R.; Tsai, M.H. Advanced anticorrosive coatings prepared from electroactive polyimide/graphene nanocomposites with synergistic effects of redox catalytic capability and gas barrier properties. Express Polym. Lett. 2014, 8, 243-255.

16. Singh, B.P.; Nayak, S.; Nanda, K.K.; Jena, B.K.; Bhattachariee, S.; Besra, L. The production of a corrosion resistant graphene reinforced composite coating on copper by electrophoretic deposition. Carbon 2013, 61, 47-56.

17. Bellucci, F.; Nicodemo, L.; Nicolais, L. Transport properties of polymeric materials as determined by electrical capacitance method. Polym. News 1992, 17, 272-277.

18. Bonnel, K.; le Pen, C.; Pébère, N. E.I.S. characterization of protective coatings on aluminium alloys. Electrochim. Acta 1999, 44, 4259-4267.

19. Bonora, P.L.; Defloriana, F.; Fedrizzi, L. Electrochemical impedance spectroscopy as tool for investigating underpaint corrosion. Electrochim. Acta 1996, 41, 1073-1082.

20. Zhang, J.; Hu, J.; Zhang, J.; Cao, C. Studies of water transport behavior and impedance models of epoxy-coated metals in $\mathrm{NaCl}$ solution by EIS. Prog. Org. Coat. 2004, 51, 145-151.

21. Juttner, K. Electrochemical impedance spectroscopy (EIS) of corrosion process on inhomogeneous surfaces. Electrochim. Acta 1990, 35, 1501-1508.

(C) 2015 by the authors; licensee MDPI, Basel, Switzerland. This article is an open access article distributed under the terms and conditions of the Creative Commons Attribution license (http://creativecommons.org/licenses/by/4.0/). 